\title{
LA GEOLOCALIZACIÓN Y EL DERECHO A LA PRIVACIDAD. ANÁLISIS DE LA ACCIÓN DE INCONSTITUCIONALIDAD 32/2012

\section{Orígenes de la geolocalización de Dispositivos Móviles}

El 17 de abril de 2012 se publicó en el Diario Oficial de la Federación un decreto por el que se reformaron, adicionaron y derogaron diversas disposiciones normativas, entre ellas el Código Federal de Procedimientos Penales y la Ley Federal de Telecomunicaciones. Estas reformas tuvieron el propósito de introducir la geolocalización en el ordenamiento jurídico nacional; dichas modificaciones preveían, en lo que nos interesa, lo siguiente:

1. Se adicionó el artículo 133 quáter al Código Federal de Procedimientos Penales para señalar que tratándose de investigaciones en materia de delincuencia organizada, delitos contra la salud, secuestro, extorsión o amenazas, el procurador general de la República o los servidores públicos en quienes se delegue la facultad, solicitarán por simple oficio o medios electrónicos a los concesionarios o permisionarios del servicio de telecomunicaciones la localización geográfica, en tiempo real, de los equipos de comunicación móvil asociados a una línea que se encuentren relacionados con una investigación criminal.

2. El artículo 16 de la Ley de Telecomunicaciones preveía las bases sobre las cuales tendría que llevarse a cabo una licitación pública

* Jefe del Departamento de Acciones de Inconstitucionalidad de la Comisión Nacional de los Derechos Humanos, mifp11@hotmail.com.

Fecha de recepción: 27 de julio de 2015.

Fecha de dictamen: 24 de septiembre de 2015. 
para concesiones sobre bandas de frecuencia del espectro para usos determinados y, en virtud de ello, establecía, entre otros aspectos, los requisitos que deberían cumplir los interesados para participar en la licitación. Entre otros, se exigía que el interesado debería incluir una propuesta de las acciones coordinadas con la autoridad correspondiente, que permitieran combatir los delitos de extorsión, amenazas, secuestro en cualquiera de sus modalidades o algún delito grave o relacionado con la delincuencia organizada.

3. Además, en el artículo 40 bis de esa misma ley se previó que los concesionarios o permisionarios del servicio de telecomunicaciones quedaban obligados a colaborar con las autoridades en la localización geográfica, en tiempo real, de los equipos de comunicación móvil asociados a una línea, la cual se relacionaba con investigaciones en materia de delincuencia organizada, delitos contra la salud, secuestro, extorsión o amenazas a solicitud del procurador general de la República, por lo que adicionaba el reconocimiento de dicha facultad a los procuradores de las entidades federativas o de los servidores públicos en quienes delegaran esta facultad, de conformidad con las leyes correspondientes.

Conviene precisar que las reformas señaladas, a la fecha, han quedado superadas, pues la ley Federal de Telecomunicaciones ha perdido vigencia por la entrada en vigor de la Ley Federal de Telecomunicaciones y Radiodifusión; mientras que el Código Federal de Procedimientos Penales será sustituido por el Código Nacional de Procedimientos Penales. No obstante, la figura de la geolocalización que se introdujo con las reformas del 2012 no ha desaparecido, sino que se mantiene en los nuevos ordenamientos jurídicos en México.

Es por esa razón que nos detenemos en el estudio de tales normas que regularon la figura de la geolocalización geográfica, porque las mismas fueron materia de un pronunciamiento por la Suprema Corte de Justicia de la Nación, cuya vía fue una acción de inconstitucionalidad, en la demanda promovida por la Comisión Nacional de los Derechos Humanos, que se radicó con el número de expediente 32/2012.

\section{LA DEMANDA DE ACCIÓN DE INCONSTITUCIONALIDAD 32/20I2}

El 11 de mayo de 2012 la Comisión Nacional de los Derechos Humanos promovió ante la Suprema Corte de Justicia de la Nación una acción de 
inconstitucionalidad demandando la invalidez de los artículos 133, quáter del Código Federal de Procedimientos Penales, 16, fracción I, apartado d) y 40 bis de la Ley Federal de Telecomunicaciones, reseñados en el acápite precedente.

La Comisión Nacional señaló dichas normas como violatorias del derecho humano a la privacidad, consagrado en los artículos 16 de la Constitución Política de los Estados Unidos Mexicanos, 11 de la Convención Americana sobre Derechos Humanos, 17 del Pacto Internacional de Derechos Civiles y Políticos, 12 de la Declaración Universal de los Derechos Humanos, y 16 de la Convención sobre los Derechos del Niño, y por tanto contradictorias de las garantías de legalidad y seguridad jurídica.

La Comisión actora planteó dos conceptos de invalidez. En su primer concepto señaló que los artículos impugnados carecían de tres principios fundamentales, que convertían la geolocalización en una medida arbitraria, los cuales eran los siguientes:

1. Falta de participación de la autoridad judicial en la autorización, supervisión y revocación de la solicitud de localización geográfica de un equipo de comunicación móvil.

2. Falta de precisión de los sujetos destinatarios de la medida porque el artículo 40 bis de la Ley Federal de Telecomunicaciones resultaba una norma abierta que no establecía quiénes pueden ser sujetos de la misma pudiendo comprender un amplio rango de personas, incluso de terceros no sospechosos en la investigación.

3. Falta precisión de un límite temporal de duración. Esa falta de límite temporal la convertiría en una atribución arbitraria susceptible de abuso de quien la tuviera a su cargo.

En un segundo concepto de invalidez se impugnó el artículo 16 de la Ley Federal de Telecomunicaciones, pues a juicio del organismo nacional carecía de precisión, llegando al extremo de poder considerar que la geolocalización se podía ejercer también en investigaciones relacionadas con cualquier delito grave, lo que resultaría desafortunado desde la perspectiva del derecho a la privacidad y la protección de datos personales.

\section{Resolución De LA ACCión DE InCONSTitucionalidAd 32/20I2}

Los días 9, 13, 14 y 16 de enero de 2014, la referida acción de inconstitucionalidad fue discutida por el Pleno de la Suprema Corte de Justicia de la 
Nación. De dicha resolución destacan algunas consideraciones que enseguida se reseñan:

Por principio de cuentas la sentencia señala que la medida tiene un fin constitucionalmente válido. La finalidad de la geolocalización es la persecución de los delitos, por lo que las facultades que la Constitución federal y las leyes nacionales confieren al Ministerio Público hacen concluir que la localización de un equipo de comunicación móvil asociado a una línea se inserta dentro de las actividades y diligencias propias de la investigación de hechos probablemente constitutivos de delitos, incluso mediante el uso de tecnologías disponibles en materia de telecomunicaciones, como aquellas con las que deben contar los concesionarios o permisionarios de - ese servicio, que pueden facilitar y hacer eficaz la persecución de los delitos. Es así que en un inicio la sentencia sostiene que no se vulneraba el derecho a la privacidad de ninguna persona, porque la medida no está dirigida a localizar personas sino un aparato de comunicación móvil.

Ante ello, en la discusión se opuso la idea de que si bien es cierto que la geolocalización está dirigida al aparato, lo cierto es que de manera indirecta implica la localización de quien acciona dicho instrumento en un momento específico.

De esa forma, la sentencia precisó que un análisis literal de la norma permite afirmar que su objeto se contrae a localizar la ubicación de un equipo terminal móvil en el momento preciso en que se utiliza por estar asociado a una línea telefónica determinada, esto es, tiene por objeto conocer el lugar aproximado desde el cual se origina una llamada proveniente de un teléfono móvil. Así, puede pensarse que la medida se constriñe a tal objeto y que su uso procede sólo en caso de que los equipos móviles, asociados a una línea se encuentren relacionados en las investigaciones de delincuencia organizada, delitos contra la salud, secuestro, extorsión o amenazas.

Después, la resolución expone que en el caso de que se llegara a afirmar que la geolocalización puede ubicar personas, eso sería de manera secundaria e indirecta, no se violaría el derecho a la intimidad, pues no se profundiza al contenido de las llamadas telefónicas, sino que sencillamente se trata de la localización en tiempo real de un instrumento de delito, que posteriormente llevará a identificar la responsabilidad penal del responsable. Sin embargo, tal escenario quedaría justificado bajo un examen de constitucionalidad, ante la necesidad de la localización inmediata del aparato donde se realiza la llamada, pues de ello depende la seguridad de las víctimas del delito. 
En esta hipótesis, la posible restricción a la vida privada de una persona que pudiera tener lugar al solicitarse la localización de un equipo de comunicación móvil, cede con el interés de preservar el orden público y la paz social, y sobre todo para garantizar la protección de los derechos de las víctimas y la eficaz investigación de los delitos.

De ahí resulta idónea la geolocalización, en la medida que no requiere para su uso autorización judicial, pues ese uso discrecional del Ministerio Público se constituye en un medio apto para alcanzar el fin perseguido, oportunidad con la que es necesario actuar en aras de salvaguardar la vida o integridad física de las víctimas del delito, o bien, evitar que se oculte o desaparezca el objeto o instrumentos del ilícito, casos en los cuales se torna prioritario el actuar con oportunidad.

Además, se precisó que el ejercicio de la facultad que confiere el Código Federal de Procedimientos Penales al procurador general de la República y a quienes éste delegue, como todo acto de autoridad, debe ajustarse a lo que dispone el primer párrafo del artículo 16 de la Constitución federal, sin que sea necesaria la intervención judicial, pues no se trata de un acto privativo sino de uno de molestia. Por tanto basta hacer constar por escrito de la autoridad competente, que funde y motive la causa legal del procedimiento, la solicitud de localización de un equipo móvil, ya que la norma le impone la obligación de formular tal solicitud en forma escrita o por medios electrónicos.

Sobre la falta de precisión en el alcance de la medida, por cuanto a los sujetos que pueden ser destinatarios de la localización de un equipo de comunicación, la resolución señala que tal precisión es innecesaria, pues serán los elementos que aporte a la investigación los que produzcan como resultado el conocimiento de quién o quiénes hacen uso del equipo de comunicación móvil, en cuyo caso la autoridad deberá solicitar otras medidas en la indagatoria a su cargo, una vez identificados los probables responsables de los delitos que se investigan y las circunstancias del caso.

También se desestimó la falta de precisión en el alcance de la medida, en cuanto al límite temporal de duración, porque se consideró que si la disposición tiene por objeto la ubicación geográfica de un equipo de comunicación móvil en tiempo real, la misma se agota en el momento en que se determina la posible localización del equipo de comunicación.

Finalmente, la Corte procedió a hacer una interpretación conforme, donde señaló que de acuerdo con la Constitución, la geolocalización se autoriza en casos excepcionales y de vigente necesidad, bien sea que se encuentre en riesgo la vida o integridad física de las víctimas del delito o cuando exista riesgo de que se oculte o desaparezca el objeto del mismo, 
además de que como todo acto de autoridad, no se exime al Ministerio Público de cumplir con la debida fundamentación y motivación de las solicitudes que emita.

Es así que la sentencia, en un ejercicio sui generis, señala que la geolocalización en modo alguno constituye una restricción a la vida privada de las personas, por estar dirigida a ubicar los equipos móviles de comunicación; posteriormente se concentra en un examen de control de constitucionalidad, donde las normas resultan válidas por atender a los criterios del fin legítimo, idoneidad, necesidad y proporcionalidad, para concluir con una interpretación de las normas de conformidad con la propia Constitución.

Por lo que se concluyó que la localización geográfica en tiempo real, no trastoca derechos fundamentales, ni siquiera en el caso de que la geolocalización derive en la localización de una persona.

\section{INTERPRETACIÓN CONFORME}

Como ya se dijo, aun cuando la sentencia reconoce como válidas las normas que instrumentan la geolocalización, para un mayor abundamiento la Suprema Corte de Justicia de la Nación puntualizó que aun reconociendo que las mismas pudieran constituir una intromisión al ámbito privado de los individuos, se satisfacen los parámetros de razonabilidad y proporcionalidad determinados en un ejercicio del control de constitucionalidad.

De esa forma, se dijo que si bien es cierto que por regla general toda invasión al derecho a la privacidad requiere una orden judicial, puede prescindirse de ésta en casos de urgencia, esto es, a) cuando se pongan en riesgo la vida o integridad física de las víctimas del delito, o bien, b) cuando exista riesgo de que se oculte o desaparezca el objeto del delito.

Las normas impugnadas, dijo la Suprema Corte, son constitucionales si y sólo si se interpreta que las mismas tienen aplicación únicamente en estos supuestos de excepción, lo cual deberá estar suficientemente motivado por la autoridad competente.

No obstante de la obvia necesidad de que en algunos casos la geolocalización deba dictarse con la premura requerida para proteger a las víctimas o preservar la identificación del lugar en que se origina una llamada, no se puede relevar a la autoridad ministerial de su obligación constitucional de fundar y motivar sus actos, concretamente mediante:

1. La instrucción al personal técnico que corresponda, que mínimamente razone la excepcionalidad del caso, dado el tipo de delitos que se investiga; 
2. La averiguación previa en la que se provee la medida, y

3. Las condiciones fácticas que revelen la eventualidad del daño a las personas o del ocultamiento de datos para esclarecer los hechos de la investigación.

De todo esto habrá de dejarse constancia en el expediente, cuya información deberá mantenerse en sigilo hasta el momento procesal oportuno, de modo que ni aun el concesionario o permisionario del servicio puedan acceder a ella.

En este ejercicio de interpretación conforme, la sentencia que resuelve la acción de inconstitucionalidad 32/2012, la Suprema Corte en su carácter de máximo y último intérprete constitucional, fija claros límites para el uso de la geolocalización en las investigaciones de delitos.

\section{EL DERECHO A LA PRIVACIDAD}

Hasta este punto resulta claro que la mayoría del Pleno de la Suprema Corte de Justicia de la Nación determinó que la medida de geolocalización, por su sola naturaleza y alcance, no es restrictiva del derecho a la vida privada.

No obstante, se insistió en recalcar en el Pleno de este alto tribunal, que aun cuando así pudiera apreciarse no debe omitirse que el derecho a la vida privada no es un derecho absoluto y, por lo tanto, puede ser restringido por el Estado siempre que:

1. Las injerencias estén previstas en la ley, y que no sean abusivas o arbitrarias;

2. Que obedezcan a fin legítimo y que sean necesarias en una sociedad democrática.

De los requisitos que se cubren en el caso de la localización geográfica se concluye que la geolocalización no resulta violatoria del derecho a la intimidad de las personas pues:

1. No se encuentra dirigida a buscar personas sino un instrumento del delito.

2. Suponiendo que alguna información privada pudiera ser revelada con el uso de esa medida, la misma resulta justificable por los fines constitucionales que persigue, a saber, la seguridad de las víctimas, y la persecución y sanción de ilícitos penales. 
3. Además, el máximo tribunal nacional fijó límites a la atribución del Ministerio Público, ya que deberán dejar constancia de dicha solicitud en el expediente de la investigación respectiva, y motivar el requerimiento sólo en casos de extrema urgencia, es decir:

a) Cuando esté en riesgo la vida o la integridad física de una persona.

b) Cuando pueda ocultarse o desaparecer el objeto de la investigación.

c) Siempre que se trate de delitos como secuestro, amenazas, crimen organizado, delitos contra la salud o una extorsión.

Aunado a que en la solicitud que se formule a los concesionarios o permisionarios de telecomunicaciones se deberá exponer mínimamente las razones del caso y el riesgo que se corre si la geolocalización no se lleva a cabo en el momento requerido.

\section{LA GEOLOCALIZACIÓN EN EL MARCO JURÍDICO VIGENTE}

Hasta aquí el análisis de la acción de inconstitucionalidad 32/2012 parecería tener por concluido el asunto de la geolocalización pero no es así, pues el 5 de marzo de 2014, en términos similares, fue incluida la geolocalización en el artículo 303 del Código Nacional de Procedimientos Penales, que establece que cuando exista denuncia o querella, bajo su más estricta responsabilidad, el procurador o el servidor público en quien delegue la facultad, solicitará a los concesionarios o permisionarios o comercializadoras, vía satélite, la localización geográfica en tiempo real de los equipos de comunicación móvil asociados a una línea que se encuentren relacionados con los hechos que se investigan.

No obstante, es necesario realizar una comparación de los normas de referencia en sus respectivos artículos:

\begin{tabular}{|c|c|}
\hline $\begin{array}{c}\text { Código Federal de Procedimientos } \\
\text { Penales }\end{array}$ & $\begin{array}{c}\text { Código Nacional de Procedimientos } \\
\text { Penales }\end{array}$ \\
\hline $\begin{array}{l}\text { Artículo 133 Quáter. Tratándose de } \\
\text { investigaciones en materia de delin- } \\
\text { cuencia organizada, delitos contra la } \\
\text { salud, secuestro, extorsión o amenazas, }\end{array}$ & $\begin{array}{l}\text { Artículo 303. Localización geográfica } \\
\text { en tiempo real. } \\
\text { Cuando exista denuncia o querella, y } \\
\text { bajo su más estricta responsabilidad, }\end{array}$ \\
\hline
\end{tabular}




\begin{tabular}{|c|c|}
\hline $\begin{array}{c}\text { Código Federal de Procedimientos } \\
\text { Penales }\end{array}$ & $\begin{array}{c}\text { Código Nacional de Procedimientos } \\
\text { Penales }\end{array}$ \\
\hline $\begin{array}{l}\text { el Procurador General de la República } \\
\text { o los servidores públicos en quienes } \\
\text { delegue la facultad, solicitarán por } \\
\text { simple oficio o medios electrónicos a } \\
\text { los concesionarios o permisionarios del } \\
\text { servicio de telecomunicaciones la lo- } \\
\text { calización geográfica, en tiempo real, } \\
\text { de los equipos de comunicación móvil } \\
\text { asociados a una línea, que se encuen- } \\
\text { tren relacionados. } \\
\text { De todas las solicitudes, la autoridad } \\
\text { dejará constancia en autos y las man- } \\
\text { tendrá en sigilo. } \\
\text { En ningún caso podrá desentenderse } \\
\text { la solicitud y toda omisión imputable } \\
\text { al concesionario o permisionarios, será } \\
\text { sancionada en términos de lo previsto } \\
\text { por el artículo } 178 \text { Bis del Código Penal } \\
\text { Federal. } \\
\text { Se castigará a la autoridad investigadora } \\
\text { que utilice los datos e información } \\
\text { obtenidos como resultado de localiza- } \\
\text { ción geográfica de equipos de comu- } \\
\text { nicación móvil para fines distintos a los } \\
\text { señalados en este artículo, en términos } \\
\text { de lo establecido en la fracción IV del } \\
\text { artículo } 214 \text { del Código Penal Federal. }\end{array}$ & $\begin{array}{l}\text { el Procurador, o el servidor público en } \\
\text { quien se delegue la facultad, solicitará } \\
\text { a los concesionarios o permisionarios } \\
\text { o comercializadoras del servicio de } \\
\text { telecomunicaciones o comunicación } \\
\text { vía satélite, la localización geográfica } \\
\text { en tiempo real de los equipos de } \\
\text { comunicación móvil asociados a una } \\
\text { línea que se encuentren relacionados } \\
\text { con los hechos que se investigan en } \\
\text { términos de las disposiciones aplicables. } \\
\text { Asimismo, se le podrá requerir la } \\
\text { conservación inmediata de datos } \\
\text { contenidos en redes, sistemas o equipos } \\
\text { de informática, hasta por un tiempo } \\
\text { máximo de noventa días en los casos } \\
\text { de delitos relacionados o cometidos con } \\
\text { medios informáticos. }\end{array}$ \\
\hline
\end{tabular}

Del ejercicio de comparación entre ambas disposiciones normativas destaca lo siguiente:

1. El artículo 133 quáter del Código de Procedimientos Federales señala que la localización geográfica es procedente sólo tratándose de investigaciones en materia de delincuencia organizada, delitos contra la salud, secuestro, extorsión o amenazas.

En cambio, la norma prevista en el Código Nacional de Procedimientos Penales omite restringir su uso para la investigación de determinados delitos, y parece decir que sólo basta la existencia de una denuncia o de una querella para solicitar su uso. 
En contraste, la Suprema Corte de Justicia de la Nación al resolver la acción de inconstitucionalidad 32/2012, precisó mediante interpretación conforme que la medida era válida si y sólo si se utilizara para la investigación de delitos relacionados con delincuencia organizada, delitos contra la salud, secuestro, extorsión o amenazas.

2. La norma del Código Nacional no indica que de todas las solicitudes del uso de localización geográfica la autoridad dejará constancia en autos y las deberá mantener en sigilo.

En la resolución de la acción de inconstitucionalidad 32/2012, la Suprema Corte de Justicia de la Nación precisó que la medida era legal, pero que no se eximía de hacer constar por escrito el hecho de que de la autoridad competente, funde y motive la causa legal del procedimiento para solicitar la localización de un equipo móvil, tal como le imponía el artículo 133 quáter del Código Federal de Procedimientos Penales respecto a la obligación de formular tal solicitud en forma escrita o por medios electrónicos.

3. El dispositivo legal del Código Nacional de Procedimientos Penales no señala sanciones penales en caso de que se hiciera un uso indebido de la misma o de la información que con su uso se obtuviera, como en cambio sí hizo el Código Federal de Procedimientos Penales.

De las anteriores observaciones podemos inferir que el artículo 303 del Código Nacional de Procedimientos Penales se trata en verdad de un nuevo acto legislativo, que como tal es susceptible de impugnación y de un pronunciamiento específico por parte del máximo tribunal nacional, donde de nueva cuenta pudieran analizarse todos y cada uno de los puntos antes señalados.

Es así que, antes de ese nuevo acto legislativo, la Comisión Nacional de los Derechos Humanos promovió acción de inconstitucionalidad en contra del artículo 303 del Código Nacional de Procedimientos Penales, la cual se radicó con el número 10/2014. Al mismo tiempo, el Instituto Federal de Acceso a la Información promovió acción de inconstitucionalidad, la cual se radicó con el número 11/2014 y se mandó acumular a la primera de las demandas mencionadas.

No obstante, la cuestión resulta interesante, porque si bien es cierto se aprecian obvias diferencias entre el precepto que preveía la geolocalización en el Código Federal de Procedimientos Penales y la emanada del Código Nacional de Procedimientos Penales, lo cierto es que existe un pronunciamiento previo por la Corte que no podrá soslayarse en un punto medular, el cual es que no existen derechos absolutos y en todo caso la 
geolocalización como una medida restrictiva del derecho a la privacidad es válida.

Posteriormente, el 14 de julio de 2014, se publicó en el Diario Oficial de la Federación la Ley Federal de Telecomunicaciones y Radiodifusión; de ella se señalaron disposiciones que podían ser estimadas como accesorias e instrumentales en la localización geográfica prevista en el Código Nacional de Procedimientos Penales, pero no fueron materia de impugnación.

Sin embargo, aunque no fue impugnada vía acción de inconstitucionalidad por ninguno de los sujetos constitucionalmente legitimados para ello, en caso de que la Suprema Corte de Justicia de la Nación determinara la invalidez del cuestionado artículo 303, podría hacer extensiva la invalidez a algunos artículos de la Ley Federal de Telecomunicaciones y Radiodifusión, mediante un ejercicio indirecto de invalidez de las normas.

La invalidez indirecta de una norma se da de acuerdo con la jurisprudencia P./J. 53/2010 del rubro "Controversias CONSTITUCiONALES y aCCiONES DE INCONSTITUCIONALIDAD. CRITERIOS PARA DETERMINAR LA INVALIDEZ INDIRECTA DE LAS NORMAS, ES EL EJERCICIO DONDE LA INVALIDEZ SE ORIGINA A PARTIR DE LA EXTENSIÓN DE LOS EFECTOS DE LA INVALIDEZ DE OTRA NORMA".

Este modelo está previsto en el artículo 41, fracción IV, de la Ley Reglamentaria de las Fracciones I y II del Artículo 105 de la Constitución Política de los Estados Unidos Mexicanos. La condición necesaria para que se extiendan los efectos de invalidez de una primera norma declarada inválida es la relación de dependencia de validez entre esta norma y otra, u otras del sistema, acorde con los diversos criterios, entre ellos el material y horizontal en el que una norma invalidada afecta a otra de su misma jerarquía debido a que ésta regula alguna cuestión prevista en aquélla, de suerte que la segunda ya no tiene razón de ser.

Por tanto, en el caso de que la Suprema Corte de Justicia determine que la figura de la geolocalización prevista en el artículo 303 del Código Nacional es inválida, como nuevo acto legislativo podrá hacer efectiva la invalidez del artículo 190, fracción I, de la Ley Federal de Telecomunicaciones y Radiodifusión, como ley de igual jerarquía que guarda relación con la primera. Pero ello quedará sujeto a que una votación calificada de ocho ministros así lo determine.

\section{CONClusiones}

El Pleno de la Suprema Corte de Justicia de la Nación al resolver la acción de inconstitucionalidad 32/2012 determinó que en la geolocalización existe 


\section{MOISÉS ISRAEL FLORES PACHECO}

una búsqueda que se refiere a los equipos de comunicación móvil y no a personas, por tanto, de ningún modo constituye una restricción a la vida privada de las personas, ya que no se encuentra dirigida a buscar personas sino un instrumento del delito.

Es la sentencia que resolvió la acción 32/2012, luego del razonamiento antes precisado, la Corte se concentra en un examen de control de constitucionalidad, donde las normas que prevén la geolocalización resultan válidas para atender a los criterios de fin legítimo, idoneidad, necesidad y proporcionalidad. De modo que suponiendo que alguna información privada pudiera ser revelada con el uso de esta medida, la misma resulta justifi- cable por los fines constitucionales que persigue, a saber: la seguridad de - las víctimas y la persecución, y sanción de ilícitos penales.

De igual forma, el tribunal constitucional realizó una interpretación de las normas de conformidad con la propia Constitución. Así, las normas impugnadas, dijo la Suprema Corte, son constitucionales si y sólo si se interpreta que las mismas tienen aplicación únicamente en estos supuestos de excepción, lo cual deberá estar suficientemente motivado por la autoridad competente.

En consecuencia, el máximo tribunal nacional fijó límites a la atribución del Ministerio Público, ya que deberán dejar constancia de dicha solicitud en el expediente de la investigación respectiva, y motivar el requerimiento sólo en casos de extrema urgencia, es decir:

- Cuando esté en riesgo la vida o la integridad física de una persona.

- Cuando pueda ocultarse o desaparecer el objeto de la investigación.

- Siempre que se trate de delitos como secuestro, amenazas, crimen organizado, delitos contra la salud o extorsión.

El artículo 303 del Código Nacional de Procedimientos Penales es un nuevo acto legislativo susceptible de impugnación y de un pronunciamiento específico por parte del máximo tribunal nacional, donde de nueva cuenta pudieran analizarse los puntos antes señalados al resolver las acciones de inconstitucionalidad 10/2014 y su acumulada 11/2014. 